\title{
Speed Guidance and Trajectory Optimization of Traffic Flow in a Low-Visibility Zone of a Highway Segment within Multiple Signalized Intersections
}

\author{
Heng Ding $(\mathbb{D}$, Yajie Cheng, Xiaoyan Zheng, Wenjuan Huang, Jiye Li, and Hanyu Yuan \\ School of Automotive and Transportation Engineering, Hefei University of Technology, Hefei 230009, China \\ Correspondence should be addressed to Heng Ding; dingheng@hfut.edu.cn
}

Received 22 February 2021; Revised 6 May 2021; Accepted 1 June 2021; Published 12 June 2021

Academic Editor: Sheng Jin

Copyright (c) 2021 Heng Ding et al. This is an open access article distributed under the Creative Commons Attribution License, which permits unrestricted use, distribution, and reproduction in any medium, provided the original work is properly cited.

\begin{abstract}
In a low-visibility environment, the speed of traffic flow is more discrete on highways, which easily causes traffic accidents. To improve the safety and efficiency level of low-visibility zones on highways, a comprehensive optimization control method is proposed. The method uses formations of a low-visibility zone to queue discrete vehicles from the upstream intersection. Then, according to the relationship between the arrival time of the fleet and the phase state of the intersection, speed guidance and trajectory optimization are carried out to improve the traffic efficiency of the fleet that enters the low-visibility zone. Finally, a lowvisibility zone of a highway segment is analysed with different traffic flows for the main road and the secondary roads, and the results show that the proposed optimization control method can prevent trajectory overlap and effectively decrease traffic delays on highways.
\end{abstract}

\section{Introduction}

Highways are an important intercity traffic link for the transportation of passengers and freight, and they have a remarkable distributed function. The composition of mixed categories of vehicles travelling on highways is complex, which causes a dispersed speed distribution of the vehicles. The visible distance can be reduced by fog and heavy precipitation, as well as wind-blown snow, dust, or smoke. The speed variance can also increase. Especially in a low-visibility environment where the visible distance is less than $200 \mathrm{~m}$, a driver cannot effectively judge the running state of a preceding vehicle, which can affect the normal operation of the traffic flow [1]. The complex situation of low visibility and discrete speed reduces the level of highway traffic safety. Statistical data have shown that traffic accidents caused by severe weather, such as fog, account for $15 \%-25 \%$ of road traffic accidents; the death rate is up to $40 \%$ higher in a few frequently foggy highway segments [2]. Hjelkrem and Ryeng [3] showed that low-visibility weather presented a greater risk for safe car following. Low-visibility weather can also easily lead to erroneous driver manoeuvres such as overreactions, physiological fluctuations, and psychological fluctuations, which can be reflected in driving safety [4]. Yannis et al. [5] noted that accident severity increased with a reduction in visibility. Therefore, the traffic safety problem of highways in low-visibility environments is very serious.

Speed is often considered the most intuitive characteristic value affected by the weather. Speed dispersion caused by a low-visibility environment is a major reason for traffic accidents. The speed variance is directly proportional to the traffic accident rate, which means that, with the increase in speed variance, the accident rate also increases [6]. Larger speed variance is related to visibility reduction [7]. Several scholars have also studied the characteristics of speed dispersion in a low-visibility environment. For example, Gao et al. [8] established a driving simulator to explore the influence of hazy weather on different driving behaviours and showed that the sensitivities of drivers to speed and distance differences were significantly lower during hazy days than clear days. Li et al. [9] collected traffic flow and meteorological data of expressways in Beijing, Hong Kong, and 
Macao and found that the speed variance was smaller than that in fine weather when visibility was 100 to $200 \mathrm{~m}$. Nevertheless, the speed variance was evidently greater than that in fine weather at 50 to $100 \mathrm{~m}$. The travel following distance based on driving speed is also a major issue in traffic safety. However, a low-visibility environment reduces visual perception and hinders many drivers from maintaining a safe driving distance from the preceding car in foggy weather $[10,11]$.

Traffic efficiency is also the other parameter that should be considered when improving traffic safety in low-visibility environments. The influence of the fleet on signal control has been confirmed in related studies for optimizing intersection signals [12-14]. At the same time, some signal optimization methods have also been proposed to improve traffic efficiency and reduce traffic delays [15-17]. For instance, Liu et al. [18] proposed a fleet-based signal control method to improve traffic efficiency at intersections. A few car-following models have been established to describe the movement of a fleet under normal weather conditions $[19,20]$. In recent years, connected and automated vehicle (CAV) technologies have been used to improve driving safety and traffic efficiency in low-visibility environments [21]. For example, Han et al. [22] proposed a trajectory optimization method to reduce the total fuel consumption of a CAV platoon through a signalized intersection. To improve traffic flow throughput and driving safety, Gong et al. [23] applied a mathematical modelling method to study and control fleets mixed with human-driven vehicles and connected automatic vehicles in a dense fog environment on a highway.

The existing methods based on normal weather can barely be directly applied in low-visibility environments. To meet the demand for effective control and safety on lowvisibility highways, this paper proposes a comprehensive optimization method of vehicle formation and trajectory optimization. By mainly using speed guidance and signal induction, the vehicles in the formation can pass through a signalized intersection without stopping as much as possible. The rest of this paper is arranged as follows. Section 2 conducts formation control for upstream vehicles. Section 3 optimizes the fleet trajectory by speed guidance coupled with signal control. Section 4 discusses a case analysis, and Section 5 presents the conclusions and future work.

\section{Control Process and Parameter Declaration}

The highway segment considered in this paper is located in a densely populated area. As shown in Figure 1, a low-visibility environmental highway segment crosses many secondary roads, with intersections controlled by traffic signals. The distance between two adjacent intersections is approximately $1000 \mathrm{~m}$ to $2000 \mathrm{~m}$. The traffic flow speed distribution on the highway is relatively discrete for the high proportion of trucks. During the control process, formation can be applied at any signalized intersection upstream of the lowvisibility highway segment. If there is no signalized intersection, then a certain upstream pedestrian crossing position can be considered the control location.
In the scene, the traffic flow speed of the main road is high, and the traffic volume of the main road is remarkably larger than those of secondary roads (less than $100 \mathrm{veh} / \mathrm{h}$ ). Therefore, the control method mainly considers the priority of the main road. To a certain extent, the traffic efficiency of the main road can be increased by sacrificing the traffic efficiency of the secondary roads.

2.1. Formation Control (FC) Process. The control area is divided into three parts: guidance, formation, and lowvisibility zones (Figure 1). The control processes in accordance with the functions of the three zones are discussed as follows:

Step 1: in the guidance zone, the variable message sign issues the remaining waiting time of each lane and induces the arriving vehicle to select the formation lane with the shortest waiting time according to the signal phase state. The aims of induction are to shorten the formation time as soon as possible and to reduce vehicle delays.

Step 2: when the lead vehicle (the first vehicle of every formation) arrives at the stop line of the formation zone, the recommended fleet speed value is given from the speed range selected by the formation control scheme depending on the vehicle type. On this basis, the formation time is determined, that is, the red time of signal control. The dissipation time is calculated as the green time. The formation and dissipation processes of the fleet in the formation zone can be regarded as a signal cycle, and the vehicles arriving in a cycle in a lane can be regarded as a fleet.

Step 3: in the low-visibility zone, the fleet is given a reasonable speed limit depending on the speed of the previous fleet, and its trajectory is optimized with the signal timing of the intersection in the low-visibility zone.

2.2. Formation Parameters. To achieve formation control, three assumptions of the scene are given as follows. First, each vehicle in the fleet is barely kept at the approximate speed, and the speed of the vehicle is allowed to fluctuate slightly at the recommended interval after vehicles enter the low-visibility zone. Second, each vehicle is not allowed to break away from the fleet. Third, the fleet follows the first-in first-out rule, and no overtaking occurs between fleets.

To maintain the above assumptions, in the control process, a voice prompt system at the intersection is used to indicate requirements to the vehicle when the vehicle enters and leaves each highway segment, and the entry and exit time of the vehicle can be obtained by the monitor at the intersection. Meanwhile, human-driven vehicles do not have the intention to leave the low-visibility highway after leaving the fleet; otherwise, they will be punished. Thus, the vehicles can keep following together as a fleet.

The formation control parameters of formation time $R$, dissipation time $G$, and the longest formation $R_{\max } /$ dissipation time $G_{\max }$ are calculated as follows. 


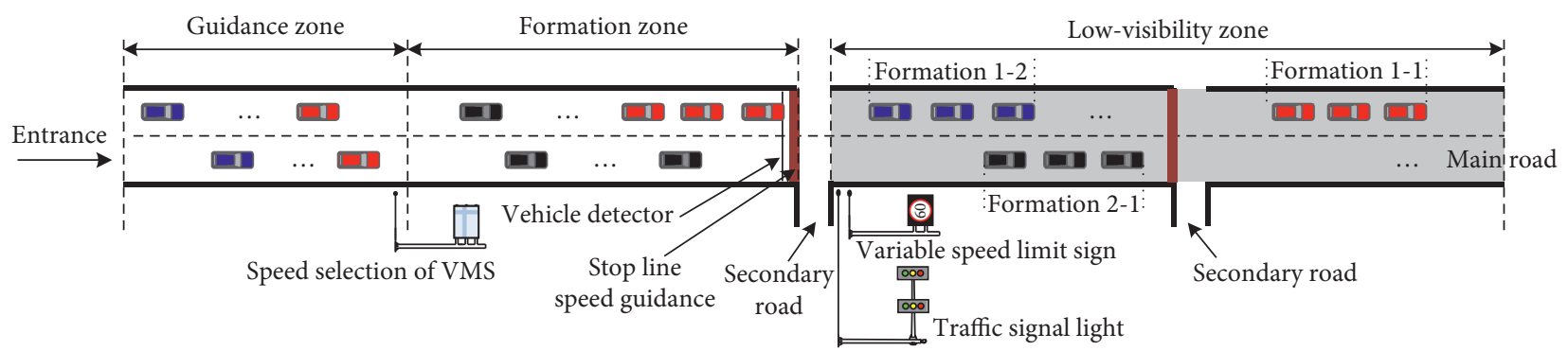

Figure 1: Control scene.

2.2.1. Formation Time. $V_{1}$ is the front fleet speed, and $V_{2}$ is the current fleet speed. If $V_{1} \geq V_{2}$, then the former and current fleets will not meet in the area, and the formation time is the minimum formation time $R_{\min }$, which is determined by the actual intersection signal control timing scheme. Otherwise, if $V_{1}<V_{2}$, then $V_{1}$ and $V_{2}$ should satisfy the following condition to ensure that the front and rear fleets do not overlap in the low-visibility zone:

$$
V_{1}\left(\frac{L}{V_{1}}-R_{0}\right)+V_{1} \cdot R_{0} \geq V_{2}\left(\frac{L}{V_{1}}-R_{0}\right),
$$

where $R_{0}$ is the fleet formation time, $h ; L$ is the length of the low-visibility segment, $\mathrm{km}$.

Considering that the minimum safety headway of the front and the rear fleet is not less than $3 \mathrm{~s}$ [24], the formation time can be expressed as

$$
R_{0} \geq \frac{L}{V_{1}}-\frac{L}{V_{2}}+\frac{3}{3600} .
$$

2.2.2. Dissipation Time. The dissipation time is related to the length of the current queue and traffic state:

$$
G_{0}=\frac{3600 n}{\left(S_{0}-q_{0}\right)}
$$

where $G_{0}$ is the fleet dissipation time, $s ; n$ is the number of queued vehicles in the current phase, veh; $S_{0}$ is the saturation flow, veh/h; and $q_{0}$ is the traffic volume of the segment, veh/ h.

2.2.3. Maximum Formation/Dissipation Time. The maximum formation time $R_{\max }$ is set according to traffic flow and intersection parameters to ensure that the fleet is not overlong. The maximum dissipation time $G_{\max }$ is set according to traffic flow.

\subsection{Vehicle Speed Constraints in Low-Visibility Zone}

2.3.1. Vehicle Speed Constraint Based on Safe Stopping Sight Distance. Under different visibility environments, the safe stopping sight distance of the vehicle should be less than the visibility [25], that is,

$$
S_{1}+S_{2}+S_{3} \leq L_{V}+S_{4}
$$

where $S_{1}$ is the distance travelled by the rear vehicle during the reaction time $t_{1}, \mathrm{~m}$ ( $t_{1}$ is usually $\left.2.5 \mathrm{~s}\right) ; S_{2}$ is the distance travelled by the rear vehicle during the braking time $t_{2}, \mathrm{~m} ; S_{3}$ is the safety distance between the front and rear vehicles, $\mathrm{m}$ (usually $5 \mathrm{~m}$ ); $L_{V}$ is the visibility distance, $\mathrm{m}$; and $S_{4}$ is the distance travelled by the front vehicle at time $t_{1}+t_{2}, \mathrm{~m}$.

Considering that the worst traffic condition of the front vehicle is stationary, that is, $S_{4}=0$, the safe stopping sight distance of the vehicle should satisfy

$$
\begin{aligned}
& S_{1}+S_{2}+S_{3} \leq L_{V}, \\
& S_{1}=\frac{v}{3.6} \cdot t_{1}, \\
& S_{2}=\frac{v^{2}}{2 g \cdot f \cdot 3.6^{2}},
\end{aligned}
$$

where $v$ is the rear vehicle speed, $\mathrm{km} / \mathrm{h} ; g$ is the gravity acceleration, $9.8 \mathrm{~m} / \mathrm{s}^{2}$; and $f$ is the road friction coefficient, which is in the range of $(0.29,0.44)$ [26] and takes 0.3 here.

By substituting (6) and (7) into (5),

$$
\frac{v}{3.6} \cdot t_{1}+\frac{v^{2}}{2 g \cdot f \cdot 3.6^{2}}+5 \leq L_{v},
$$

further calculation of inequality (8) can be obtained: $0 \leq v \leq\left(-0.694+\sqrt{0.482+0.052 \cdot\left(L_{v}-5\right)} / 0.026\right)$.

The relationship between the maximum safe driving speed $v_{f}$ and $L_{v}$ is

$$
v_{f}=\frac{-0.694+\sqrt{0.482+0.052 \cdot\left(L_{v}-5\right)}}{0.026},
$$

where $v_{f}$ is the maximum safe driving speed (the safe free flow speed), $\mathrm{km} / \mathrm{h}$.

2.3.2. Maximum Speed Based on Traffic One-Way Driving Lane. According to the relationships among traffic volume, density, and velocity, that is, $Q=k \cdot v$ [27], the velocitydensity equation $k=f_{1}\left(v, v_{f}, k_{j}\right)$ is

$$
\mathrm{Q}=k \cdot v=f_{1}\left(v, v_{f}, k_{j}\right) \cdot v \text {. }
$$

The maximum value of $v$ is

$$
v_{\max }=f_{2}\left(Q, v_{f}, k_{j}\right),
$$

where $f_{2}$ is the inverse of $f_{1}$. 
If $(\mathrm{dQ} / \mathrm{d} k)=0$ and $(\mathrm{dQ} / \mathrm{d} v)=0$, the critical speed $v_{m}$ is

$$
\begin{aligned}
& v_{m}=f_{3}\left(v_{f}, k_{j}\right), \\
& k_{j}=f_{4}\left(k_{m}, v_{f}\right) .
\end{aligned}
$$

2.3.3. Speed Limit Model of Highway Segments in a LowVisibility Environment. Given the stopping sight distance $S=S_{1}+S_{2}+S_{3}$, when $v=v_{m}$, the corresponding stopping sight distance $S_{m}$ is

$$
S_{m}=\frac{2.5 v_{m}}{3.6}+\frac{v_{m}^{2}}{2 g \cdot f \cdot 3.6^{2}}+5=f_{5}\left(v_{m}\right) .
$$

The reciprocal of the stopping sight distance $S_{m}$ is the critical density $k_{m}$, and $S_{m}=\left(1000 N / k_{m}\right)$. $N$ takes 1 here. Then, $k_{m}=\left(1000 / S_{m}\right)$,

$$
k_{j}=f_{4}\left(k_{m}, v_{f}\right)=f_{4}\left(\frac{1000}{S_{m}}, v_{f}\right),
$$

where $v_{m}$ and $v_{f}$ have a certain relationship, that is, $v_{m}=f_{6}\left(v_{f}\right)$. Accordingly, (14) can described as

$$
k_{j}=f_{4}\left(\frac{1000}{f_{5}\left(v_{m}\right)}, v_{f}\right)=f_{4}\left(\frac{1000}{f_{5}\left(f_{6}\left(v_{f}\right)\right)}, v_{f}\right) \text {. }
$$

By substituting (9) and (15) into (11), the relationship between $v_{\max }$ and $Q$, which is the speed-limiting model considering the visual distance of low-visibility and traffic flow, is

$$
v_{\max }=f_{2}\left(Q, \frac{-0.694+\sqrt{0.482+0.052 \cdot\left(L_{V}-5\right)}}{0.026}, f_{4}\left(\frac{1000}{f_{5}\left(f_{6}\left(v_{f}\right)\right)}, v_{f}\right)\right)
$$

If (10) uses the Greenshield velocity-density equation, (16) can be described as

$$
v_{\max }=\frac{1}{2} v_{f}\left(1+\sqrt{1-\frac{Q\left(0.347 v_{f}+0.003 v_{f}^{2}+5\right)}{500 v_{f}}}\right) .
$$

Taking the single lane traffic volume of $600 \mathrm{veh} / \mathrm{h}$ as an example, the theoretical recommended speed limit value is calculated. The result is shown in Table 1.

\section{Trajectory Optimization of Fleet in Low- Visibility Zone}

If there is no intersection in the low-visibility highway segment (Figure 1), driving safety and traffic efficiency can be improved by the abovementioned formation control. If there are a few intersections in the low-visibility highway segment, the signal timing of the intersection and fleet speed should be adjusted in combination with the arrival fleet to reduce the influence of the intersections on the trajectory of the main road vehicles.

3.1. Detector Settings. Figure 2 shows that two types of detectors, namely, vehicle and fleet detectors, are established at the intersection. $d_{1}$ is the distance of the vehicle detector to the stop line, and $d_{3}$ is the distance of the fleet detector to the stop line. Speed guidance within $d_{3}$ and signal optimization control within $d_{1}$ are performed for fleets.

3.2. Speed Induction of Fleet. Speed induction is the first step of formation control in the low-visibility zone. According to the relationships of the arriving fleet speed with 9 signal states of the downstream intersection, the speed guidance of the fleet is shown in Figure 3.

In states $1,2,6$, and 7 , the fleet can directly pass the intersection without the need to change its movement trajectory. In states $3,4,5,8$, and 9, the fleet will encounter a red light. In this situation, trajectory optimization is important to prevent the fleet from stopping when passing the downstream intersection.

3.2.1. Speed Induction. Assume the induced speed of the fleet is $v_{g}$, the initial speed is $v_{P}$, and the length of the induced area is $d_{3}$. According to the arrival time of the fleet, the induction methods of states $3,4,5,8$, and 9 are given as follows.

(1) In state 3 (Figure 3(c)), the fleet will meet the red signal if it still drives at the current speed. In this case, the fleet should accelerate to pass the intersection, and the adjusted speed satisfies

$\frac{v_{g}-v_{P}}{a}+\frac{d_{3}-\left(v_{g}^{2}-v_{P}^{2}\right) / 2 a}{v_{g}}+\left(N_{P}-1\right) \cdot h_{P} \leq G^{\prime}$,

where $a$ is the fleet acceleration, $\mathrm{m} / \mathrm{s}^{2} ; G^{\prime}$ is the remaining green time when the fleet arrives at the fleet detector, $s$.

(2) In state 4 (Figure 3(d)), the fleet has difficulty accelerating through the intersection during the last green light. The optimal scheme controls the fleet arriving at the next green light, and the adjusted speed satisfies 
TABLE 1: Low-visibility speed limit.

\begin{tabular}{lccc}
\hline Visibility $(\mathrm{m})$ & Calculated value $(\mathrm{km} / \mathrm{h})$ & Theoretical recommended value $(\mathrm{km} / \mathrm{h})$ & Utah speed limit $(\mathrm{km} / \mathrm{h})$ \\
\hline$<50$ & Suggest road closure & No entry & 40 \\
$50 \sim 100$ & $41 \sim 66$ & $40 \sim 65$ & 50 \\
$100 \sim 150$ & $66 \sim 87$ & $65 \sim 85$ & 65 \\
$150 \sim 200$ & $87 \sim 104$ & $85 \sim 100$ & 80 \\
$>200$ & Normal driving & Normal driving & Normal driving \\
\hline
\end{tabular}

Note: the calculated value and the theoretical recommended value do not consider the speed limit of the highway segment.

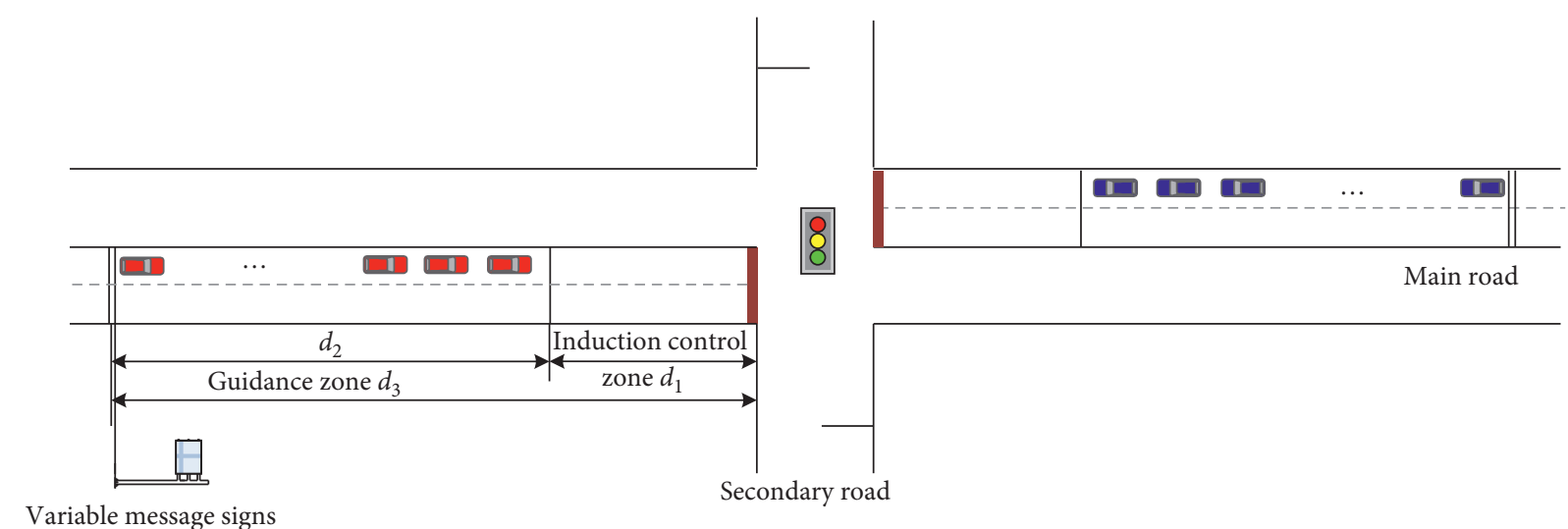

$$
\begin{aligned}
& \text { Stop line } \\
& \text { — Vehicle detector } \\
& =\text { Fleet detector }
\end{aligned}
$$

Figure 2: Detector distribution at the intersection of low-visibility road segments.

$$
G^{\prime}+R_{N}+T_{d}^{1} \leq \frac{v_{P}-v_{g}}{a}+\frac{d_{3}-\left(v_{P}^{2}-v_{g}^{2}\right) / 2 a}{v_{g}}+\left(N_{P}-1\right) \cdot h_{P} \leq G^{\prime}+R_{N}+G_{N}
$$

where $R_{N}$ is the red time of the next red light phase, $s$; $G_{N}$ is the green time of the next green light phase, $s$; and $T_{d}^{1}$ is the dissipation time of the queued fleet before arriving at the intersection, $s$.

(3) In state 5 (Figure 3(e)), the signal remains red when the fleet arrives at the intersection within the current speed. At this time, the speed of the fleet should be reduced to ensure that it can pass the intersection during the green time phase. The adjusted speed meets

$$
\begin{aligned}
R^{\prime}+T_{d}^{2} & \leq \frac{v_{P}-v_{g}}{a}+\frac{d_{3}-\left(v_{P}^{2}-v_{g}^{2}\right) / 2 a}{v_{g}}+\left(N_{P}-1\right) \cdot h_{P} \\
& \leq R^{\prime}+G_{N},
\end{aligned}
$$

where $R^{\prime}$ is the remaining red time when the fleet arrives at the fleet detector, $s ; T_{d}^{2}$ is the dissipated time of the fleet that has been queued before the realtime fleet arrives at the intersection, $s$.
Notably, $T_{d}^{1}$ is a predicted value of the queue dissipation time during the red light phase that has not yet started, where a constant is taken; $T_{d}^{2}$ is a realtime variable determined by the number of queued vehicles in the current red light phase, $T_{d}^{2}=\left(H / v_{d}\right)$, where $H$ is the number of queued vehicles and $v_{d}$ is the fleet dissipation speed.

(4) In state 8 (Figure $3(\mathrm{~h})$ ), the fleet should accelerate through the intersection, and the adjusted speed meets

$$
\begin{aligned}
R^{\prime}+T_{d}^{2} & \leq \frac{v_{g}-v_{P}}{a}+\frac{d_{3}-\left(v_{g}^{2}-v_{P}^{2}\right) / 2 a}{v_{g}}+\left(N_{P}-1\right) \cdot h_{P} \\
& \leq R^{\prime}+G_{N},
\end{aligned}
$$

(5) In state 9 (Figure 3(i)), similar to state 4, the fleet should decelerate to ensure its arrival at the next green light, and the adjusted speed meets

$$
R^{\prime}+G_{N}+R_{N}+T_{d}^{2} \leq \frac{v_{P}-v_{g}}{a}+\frac{d_{3}-\left(v_{P}^{2}-v_{g}^{2}\right) / 2 a}{v_{g}}+\left(N_{P}-1\right) \cdot h_{P} \leq R^{\prime}+R_{N}+2 G_{N}
$$




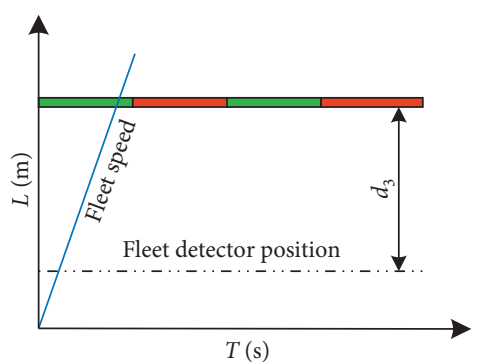

(a)

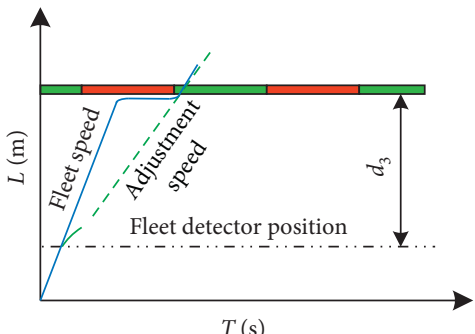

(d)

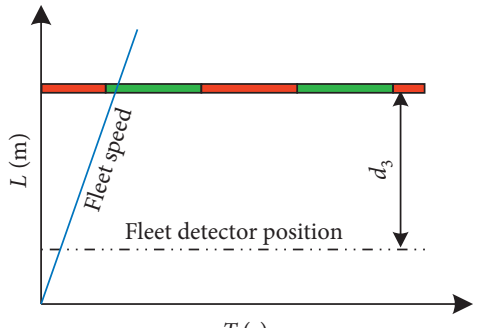

$T(\mathrm{~s})$

(g)

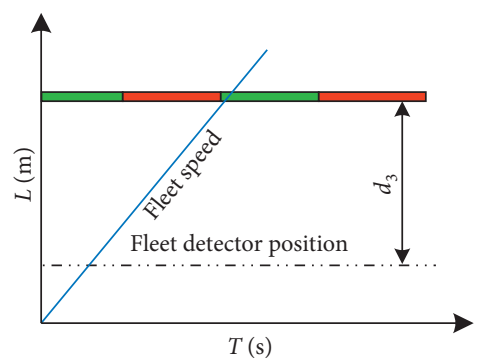

(b)

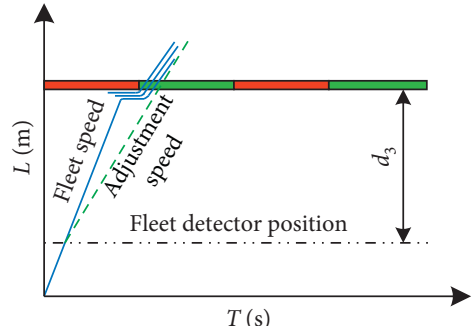

(e)

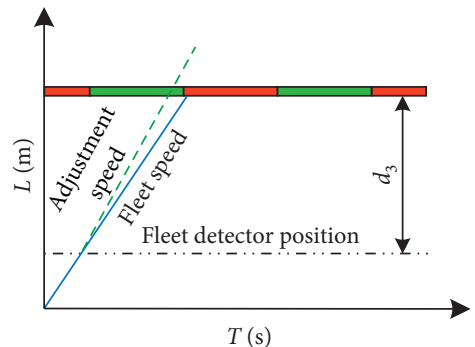

(h)

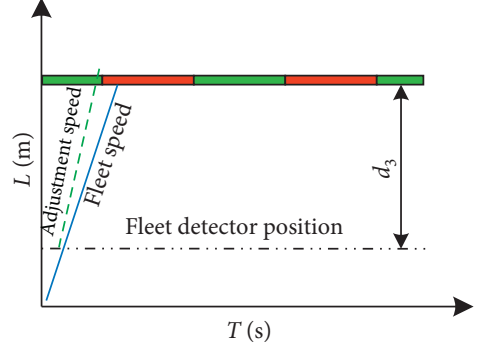

(c)

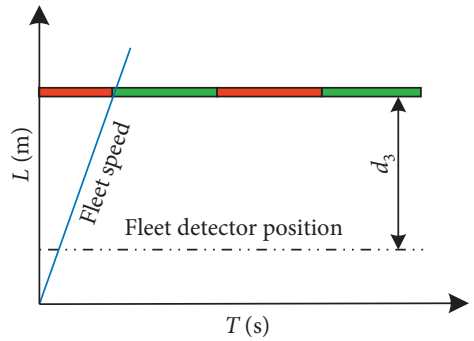

(f)

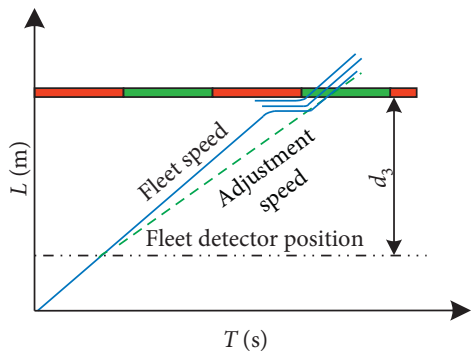

(i)

Figure 3: Speed induction of fleet. (a) State 1. (b) State 2. (c) State 3. (d) State 4. (e) State 5. (f) State 6. (g) State 7. (h) State 8. (i) State 9.

Traffic shock waves are a set describing the movement or propagation of "traffic flow state change," which is caused by external interference or an interruption of traffic flow [28]. The wave velocity equation is

$$
u_{w}=\frac{\Delta q}{\Delta k}=\frac{q_{2}-q_{1}}{k_{2}-k_{1}}=\frac{k_{2} v_{2}-k_{1} v_{1}}{k_{2}-k_{1}}
$$

where $q_{1}, k_{1}$, and $v_{1}$ are the traffic volume (pcu/h), density $(\mathrm{pcu} / \mathrm{km})$, and speed $(\mathrm{km} / \mathrm{h})$ behind the shock wave front; $q_{2}, k_{2}$, and $v_{2}$ are the traffic volume (pcu/h), density (pcu/ $\mathrm{km})$, and speed $(\mathrm{km} / \mathrm{h})$ in front of the shock wave front; and $u_{w}$ is the wave speed.

When the front fleet needs to slow down at the intersection, i.e., at states 4,5 , and 9 , the traffic shock wave will be generated to the rear fleets, which is marked as $w_{1}$. The traffic flow state of the front fleet after deceleration is $\left(q_{f}, k_{f}, v_{f}\right)$, and that of the rear fleet is $\left(q_{f}, k_{f}, v_{f}\right)$. The wave velocity equation $u_{1}$ can be expressed as

$$
u_{1}=\frac{q_{f}-q_{r}}{k_{f}-k_{r}}
$$

When $v_{f}>v_{r}$ and $q_{f}>q_{r}, k_{f}<k_{r}$, so $u_{1}<0$; that is, shock wave $w_{1}$ propagates along the opposite direction of traffic flow. At this time, there will be no clustering between the front fleet and rear fleet.

Otherwise, when $v_{f}<v_{r}$ and $q_{f}<q_{r}, k_{f}>k_{r}$, so $u_{1}<0$; that is, shock wave $w_{1}$ propagates along the opposite direction of traffic flow. At this time, there will be clustering between the front fleet and rear fleet. If the rear fleet overtakes the front fleet upstream of the intersection, the two fleets will form a team and drive through the intersection at the speed of the front fleet. If it fails to catch up with the vehicle ahead, it will accelerate to the speed before deceleration after passing the intersection.

When the front fleet stops and waits at the intersection, it will form a queue cumulative shock wave, which is recorded as $w_{2}$. Traffic flow changes from a free flow state $\left(q_{a}, k_{a}\right)$ to a blocked flow state $\left(q_{j}, k_{j}\right)$. The wave velocity equation $u_{2}$ can be expressed as

$$
u_{1}=\frac{q_{j}-q_{a}}{k_{j}-k_{a}},
$$

where $q_{a}$ and $k_{a}$ are the average arrival rate $(\mathrm{pcu} / \mathrm{h})$ and average density $(\mathrm{pcu} / \mathrm{km})$ of upstream vehicles in the cycle.

Because $q_{a}>q_{j}=0$ and $k_{j}>k_{a}, u_{1}<0$, and the shock wave travels in the opposite direction to the traffic flow. When the rear fleet follows the front fleet to stop in line, the 
rear fleet and the front fleet form a new fleet, which drives in line according to the speed of the front fleet.

3.2.2. Fleet Speed Constraints. In a low-visibility environment, the speed value of the fleet has a certain range in formation control, and this range should satisfy the condition of vehicle acceleration or deceleration. The influence of speed dispersion on traffic capacity is quantified as a correction coefficient, and the correction coefficient meets [29]

$$
f_{v}=1-0.0063 D
$$

where $f_{v}$ is the correction coefficient of the speed dispersion on traffic capacity and $D$ is the speed dispersion.

Equation (26) shows that a large speed dispersion corresponds to a small correction coefficient. The correction coefficient value and speed dispersion intervals are $[0.85$, $0.95]$ and $[7.9 \mathrm{~km} / \mathrm{h}, 23.8 \mathrm{~km} / \mathrm{h}]$, respectively, to ensure the traffic capacity. In this study, $15 \mathrm{~km} / \mathrm{h}$ is taken as the allowable variation of the speed discrete value. Therefore, the adjusted speed meets the following constraints.

(1) The adjusted fleet speed meets the speed limit of low visibility, as follows:

$$
v_{\max }-15+\gamma \leq v_{g} \leq v_{\max }
$$

where $\gamma$ is the influencing factor of the length of the low-visibility zone on the speed range selection, $\gamma \in(0,15)$.

If the speed range is too small, then the fleet is easily beyond the range after induction. Considering that fleet speed guidance is only for acceleration and deceleration of the induced area, the speed value of the low-visibility zone is not affected. The advised speed range is

$$
v_{\max }-25+\gamma \leq v_{g} \leq \min \left(v_{\max }+10, V_{\max }\right),
$$

where $V_{\max }$ is the maximum speed limit of the road segment, $\mathrm{km} / \mathrm{h}$.

(2) If the fleet accelerates, then it should not collide with the former fleet in the guidance zone $d_{3}$ to ensure that the trajectory does not overlap after guidance. The adjusted fleet speed meets

$$
v_{p} \times H_{p} \geq\left(v_{g}-V_{F}\right) \times \frac{d_{3}}{V_{F}} .
$$

If the fleet decelerates, then it should not collide with the rear fleet in the guidance zone $d_{3}$. The adjusted fleet speed meets

$$
\left(V_{B}-v_{g}\right) \times \frac{d_{3}}{v_{g}} \geq V_{B} \times H_{P},
$$

where $V_{F}$ is the previous fleet speed before the current fleet, $\mathrm{m} / \mathrm{s} ; V_{B}$ is the next fleet speed behind the current fleet, $\mathrm{m} / \mathrm{s}$.

The adjusted speed interval $v_{g} \in[\underline{v}, \bar{v}]$ can be obtained by (27)-(30), where $\underline{v}$ is the lower bound of the speed adjustment range and $\bar{v}$ is the upper bound of the speed adjustment range. If this interval exists, then the adjusted speed value of $v_{g}$ will decrease the delay of the fleet. The driving time of the fleet in the induction zone is $\left(\left|v_{g}-v_{P}\right| / a\right)+\left(d_{3}-\left(\left|v_{g}^{2}-v_{P}^{2}\right| / 2 a\right) / v_{g}\right)$, and the trip delay is $D_{T}=\left(\left|v_{g}-v_{P}\right| / a\right)+\left(d_{3}-\left(\left|v_{g}^{2}-v_{P}^{2}\right| / 2 a\right) / v_{g}\right)-\left(d_{3} / v_{\max }\right)$. Therefore, the value of $v_{g}$ satisfies

$$
\min \left(D_{T}\right)=\min \left(\frac{\left|v_{g}-v_{P}\right|}{a}+\frac{d_{3}-\left(\left|v_{g}^{2}-v_{P}^{2}\right| / 2 a\right)}{v_{g}}-\frac{d_{3}}{v_{\max }}\right), \quad v_{g} \in[\underline{v}, \bar{v}] .
$$

If the range $v_{g} \in[a, b]$ does not exist, then the vehicle will have no acceleration or deceleration chance under the constraint condition.

3.3. Signal Control Optimization. The vehicle trajectory is optimized based on formation control after the fleet speed is adjusted. Signal optimization is conducted according to the fleet arrival time, which can be divided into two situations. The first situation is that when the fleet is detected and the green light will be ended, the fleet has insufficient time to reach the intersection in the remaining green time. To avoid a stop, the green light time can be extended according to the arrival status of the fleet to allow the fleet to pass the intersection directly. In the second situation, the remaining red light time is longer than the time that the fleet travels from the vehicle detector to the stopping line, and the fleet has no deceleration space and has to wait when it arrives at the stopping line. Red light time can be shortened. The method of adjusting the green light phase in the bus priority control strategy is adopted here [30]. The red light time is also shortened according to the corresponding fleet characteristics.

\subsubsection{Parameter Settings}

(1) Green Time. The green time should satisfy the dissipation time of the fleet $[31,32]$ :

$$
G_{\min }=\max \left(G_{P}, G_{P}^{\prime}, G_{\min }^{\text {major }}\right),
$$

where $G_{P}$ is the dissipation time, $s$; and $G_{P}^{\prime}$ is the queuing dissipation time of the intersection considering the vehicle detector distance. We assume that the saturated flow rate is $Q$ veh/h, and the dissipation time can be estimated as 


$$
G_{P}^{\prime}=\frac{2 d_{1}}{\bar{l}}+\frac{3600}{Q}
$$

where $\bar{l}$ is the average queuing distance of the queued vehicles, $\mathrm{m}$, and $G_{\mathrm{min}}^{\mathrm{major}}$ is the minimum green time of the main road, $s$.

(2) Unit Green Light Extension Time. The unit green light extension time considers two situations: one is that the fleet is about to arrive at the end of the green light, and the other is that the remaining green time is insufficient to enable the entire fleet to pass the intersection. The green extension time is

$$
G_{0 i}=\frac{d_{1}}{v_{P, i}}+\left(N_{P, i}-1\right) \cdot h_{p}-G_{D}
$$

where $G_{0 i}$ is the unit green light extension time obtained by the $i$ th fleet requesting the green light, $s ; v_{P, i}$ is the fleet speed of the $i$ th fleet at the current time, $\mathrm{m} / \mathrm{s} ; N_{P, i}$ is the number of vehicles in the $i$ th fleet; and $G_{D}$ is the remaining green time of the green light phase in the intersection when fleet $i$ arrives at the vehicle detector, $s$.

(3) Unit Red Light Shortening Time. In addition to the remaining red light time and fleet speed characteristics, the dissipation time of the queuing vehicle should be considered. The shortening time of the red light is

$$
R_{0 i}=R_{D}+T_{d}-\frac{d_{1}}{v_{P, i}},
$$

where $R_{0 i}$ is the unit red light shortening time obtained by the $i$ th fleet, $s ; R_{D}$ is the remaining red light time of the current red light phase when fleet $i$ arrives at the vehicle detector, $s$; and $T_{d}$ is the dissipating time of the queue vehicle during the red light.

The shortening of the red light in the direction of the main road simultaneously reduces the green time of the secondary road direction. Notably, the green time of the secondary road should satisfy the minimum green time. In addition, the red light shortening time varies with the different values of the fleet. Then, the formation time meets

$$
R \geq 3600\left(\frac{L_{D}}{V_{1}^{\text {new }}}-\frac{L_{D}}{V_{2}^{\text {new }}}\right),
$$

where $L_{D}$ is the distance between the current signalized intersection and the next signalized intersection, $\mathrm{km} ; V_{1}^{\text {new }}$ is the front fleet speed adjusted by the current signalized intersection, $\mathrm{km} / \mathrm{h}$; and $V_{2}^{\text {new }}$ is the speed of the current fleet updated by the current signalized intersection to meet the new formation requirements, $\mathrm{km} / \mathrm{h}$.

(4) Maximum Green Time. The maximum green time of the main road is not an unlimited extension and can be set according to the traffic volume of the secondary road.

3.3.2. Phase-Switching Method. The rights of the main and secondary roads will be converted at the end of the green light extension time and when no new fleet arrivals are detected or the green time of the main road reaches the maximum green time. When the secondary road obtains the right of way, an initial minimum green time is first set. Then, the right of way is converted according to the demand information of the main road.

In the direction of the main road, one phase of the same signal control intersection corresponds to the traffic flow arriving in the opposite direction, and the traffic flows to arrive in these two directions are different. Specifically, the factors, such as the size and speed of the fleet, are different. Therefore, the green light extension time or the red light shortening time required for both directions are different. A common time should be set to meet the traffic demands in both directions. The two fleets to arrive in both directions are $N_{P, 1}$ and $N_{P, 2}$, the speeds are $v_{P, 1}$ and $v_{P, 2}$, and the times to reach the vehicle detector are $t_{P, 1}$ and $t_{P, 2}$.

If $t_{P, 1}=t_{P, 2}$, then both fleets arrive at the vehicle detector at the same time, and the unit green/red light time only needs to be extended/decreased. The value is expressed as

$$
\begin{aligned}
& G_{0}=\max \left(\frac{d_{1}}{v_{P, i}}+\left(N_{P, i}-1\right) \cdot h_{p}-G_{D}, \quad i=1,2\right), \\
& R_{0}=\max \left(R_{D}+T_{d, i}-\frac{d_{1}}{v_{P, i}}, \quad i=1,2\right) .
\end{aligned}
$$

If $t_{P, 1} \neq t_{P, 2}$, then the two fleets cannot reach the vehicle detector at the same time. Moreover, only extending/decreasing one unit of green light/red light time is insufficient. Furthermore, the extension/reduction of two units of green light/red light time will cause time coincidence. Thus, the time difference between $t_{P, 1}$ and $t_{P, 2}$ should be considered as follows:

$$
\begin{aligned}
& G_{0}=\sum_{i=1}^{2}\left(\frac{d_{1}}{v_{P, i}}+\left(N_{P, i}-1\right) \cdot h_{p}-G_{D}\right)-\left|t_{P, 1}-t_{P, 2}\right|, \\
& R_{0}=\sum_{i=1}^{2}\left(R_{D}+T_{d, i}-\frac{d_{1}}{v_{P, i}}\right)-\left|t_{P, 1}-t_{P, 2}\right| .
\end{aligned}
$$

Based on speed guidance and signal optimization, a comprehensive optimization control method of vehicles passing through multiple signalized intersections in a lowvisibility environment can be obtained. The whole control process is shown in Figure 4.

During signal control, the signal cycle is dynamic, but the maximum green time and the minimum red time are limited. When the current signal cycle ends, the cycle time and green light time of the next signal cycle update to the original time. In this paper, the speed guidance and signal timing scheme is calculated for each fleet according to the fleet speed at the detector and the current intersection signal status.

3.4. Trajectory Optimization. The purpose of trajectory optimization is to improve road traffic efficiency under the constraints of (4)-(17). For the very low traffic flow of secondary roads in highway systems, the main road traffic 


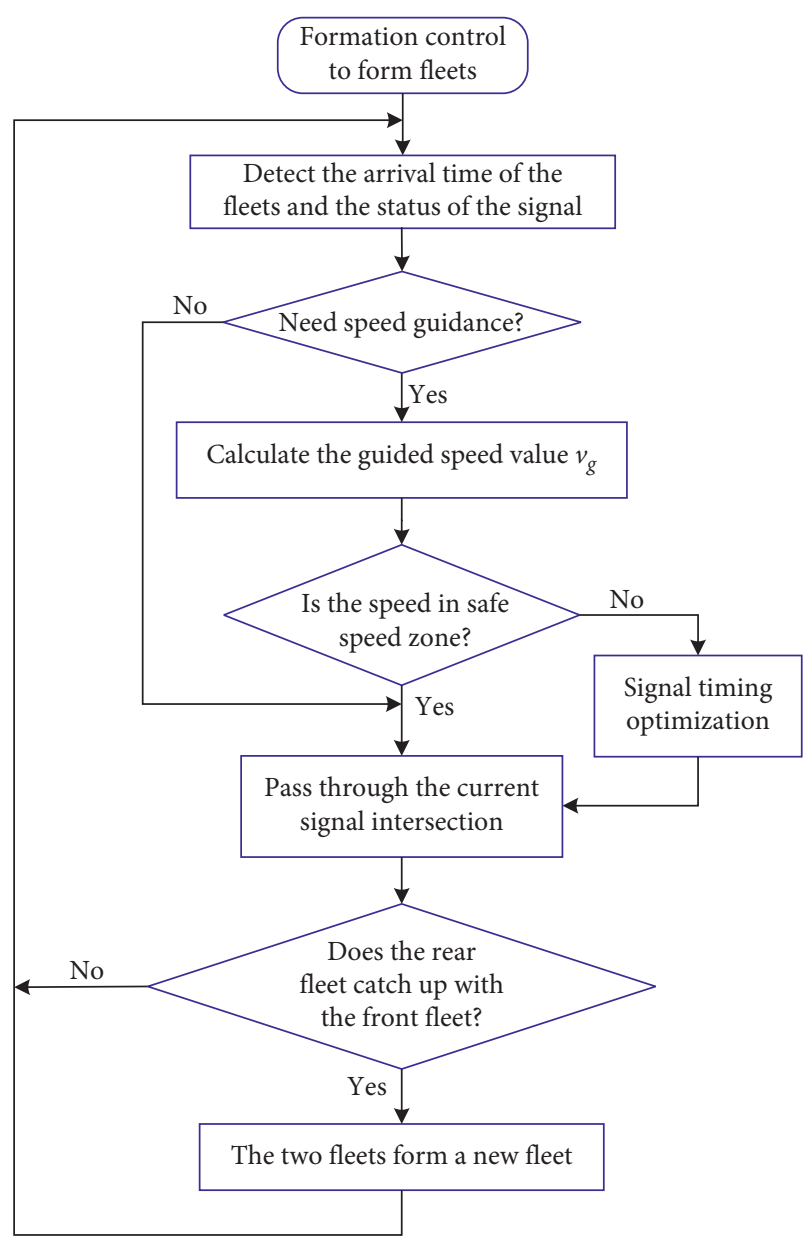

FIGURE 4: Control process of comprehensive optimization control.

delay is the main indicator used for evaluation. The main road traffic delay mainly includes the travel delay in the speed guidance zone and the parking delay of the fleet through the intersection.

The travel delay of the fleet decelerating through the guidance zone is

$$
D_{T}^{\prime}=\frac{\left|v_{g}-v_{P}\right|}{a}+\frac{d_{3}-\left(\left|v_{g}^{2}-v_{P}^{2}\right| / 2 a\right)}{v_{g}}-\frac{d_{3}}{v_{p}} .
$$

The parking delay of the fleet that cannot pass the intersection is

$$
D_{R}=\left(G^{\prime}+R^{\prime}+R\right)-\frac{d_{3}}{v_{p}}+t_{s} .
$$

When $G^{\prime} \neq 0, R^{\prime}=0$. When $R^{\prime} \neq 0, G^{\prime}=0$ and $R=0$. $t_{s}$ is the vehicle start delay time, and $t_{s}=\left(v_{p} / 2 a\right)$. If the fleet passes through the intersection without stopping, $D_{R}=0$.

Then, the main road traffic delay is

$$
D_{m}=D_{T}^{\prime}+D_{R}
$$

Therefore, the trajectory optimization objective is

$$
\min \left(D_{m}\right)=\min \left(D_{T}^{\prime}+D_{R}\right) .
$$

\section{Simulation Analysis}

The simulation scene is a $3000 \mathrm{~m}$ long highway segment with multiple intersections, and the visibility is set to $150 \mathrm{~m}$. The traffic volume in the secondary direction is $50 \mathrm{veh} / \mathrm{h}$, the minimum green time of the secondary road is $20 \mathrm{~s}$, the longest green time of the main road is $100 \mathrm{~s}$, the saturated flow of the main road is $1600 \mathrm{veh} / \mathrm{h}$, and the longest formation time is set to $100 \mathrm{~s}$. In this paper, MATLAB software is used for simulation analysis. During the simulation process, the initial vehicle headway and vehicle speed of the traffic flow are randomly generated within a fixed range. The speed constraint range during the guidance zone is calculated by (9), (14), and (27)-(30) and considers a design speed limit of $80 \mathrm{~km} / \mathrm{h}$. The guidance speed constraint range is shown in Table 2 .

4.1. Trajectory Analysis. The proposed control method comprises three parts: formation control, speed guidance, and signal optimization. Three control methods of formation control (FC), formation control-speed guidance (FCSG), and FC-SG-SO are analysed to compare the control results. In the FC method, the vehicle passes the signalized intersection of the low-visibility zone only in the form of fleets. In the FC-SG method, the vehicles enter the sensing area of the intersection in the low-visibility zone in the form of fleets. Then, the induction speed within the limited range is given according to the current signal state. The FC-SG-SO method optimizes the vehicle trajectory by controlling the signal light when the induction speed exceeds the limit range based on the FC-SG method.

During analysis of the vehicle trajectory, the traffic volume of the single lane on the main road is set to $600 \mathrm{veh} /$ h. Moreover, the expected values of fleet size, spacing, and speed are $5 \mathrm{veh}, 30 \mathrm{~s}$, and $60 \mathrm{~km} / \mathrm{h}$, respectively. According to [33], $d_{3}=600 \mathrm{~m}$ is used as the scene simulation parameter.

The proposed control methods are mainly aimed at how to pass the highway segment safely and efficiently in a lowvisibility environment. For the highway segment between two signalized intersections, if the fleet passes the current intersection by speed guidance, the fleet continues to drive at the guided speed $v_{g}$. If the fleet directly passes the current intersection at the original speed, the fleet continues to drive at the initial speed $v_{p}$. If the fleet stops at the current intersection and waits, the fleet still drives at the initial speed $v_{p}$ after restarting. If the rear fleet catches up with the front fleet, the rear fleet needs to slow down to the same speed as the front fleet, and the two fleets form a new fleet. Other fleets drive according to this rule. When the fleet arrives at the next intersection, the fleet trajectory optimization method is the same as that of the previous intersection.

The trajectories of the main road traffic flow under the three control methods are shown in Figure 5.

Figure 5(a) shows that fleets wait during the red light period of nearly every cycle when the FC method is used. Furthermore, some fleets are cut off during the green light, and not all fleets pass through the intersection. The stopping times of fleets under the FC-SG in Figure 5(b) are 
TABle 2: Control parameters.

\begin{tabular}{lcc}
\hline Main road traffic volume $(\mathrm{veh} / \mathrm{h})$ & Guidance speed range $(\mathrm{km} / \mathrm{h})$ & Minimum green time $(\mathrm{s})$ \\
\hline 400 & {$[60,80]$} & 30 \\
600 & {$[55,80]$} & 35 \\
800 & {$[50,80]$} & 40 \\
1000 & {$[45,80]$} & 45 \\
1200 & {$[40,75]$} & 50 \\
1400 & {$[35,70]$} & 55 \\
1600 & {$[30,65]$} & 60 \\
1800 & {$[25,60]$} & 65 \\
2000 & {$[20,55]$} & 70 \\
\hline
\end{tabular}

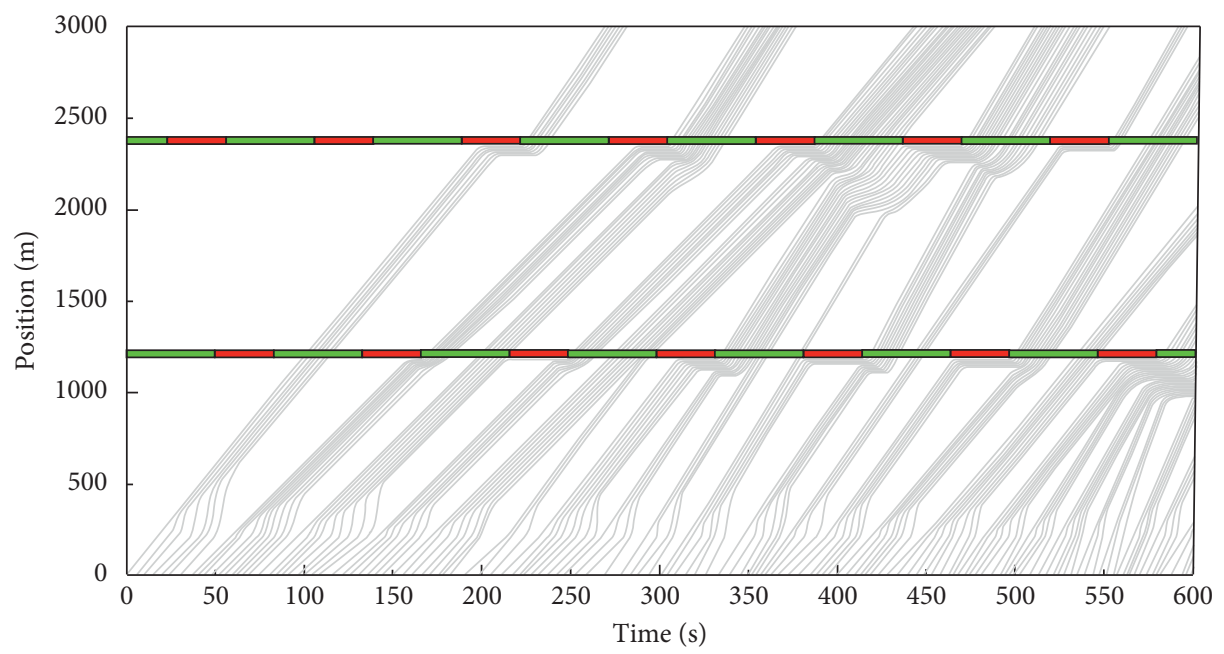

(a)

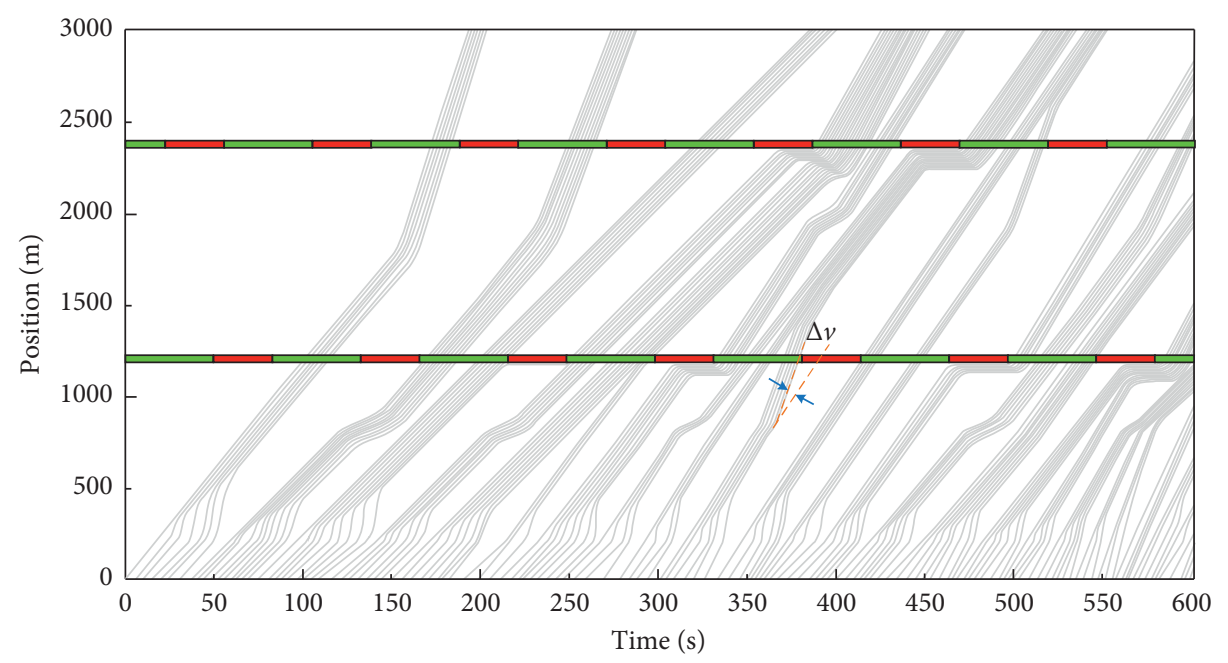

(b)

Figure 5: Continued. 


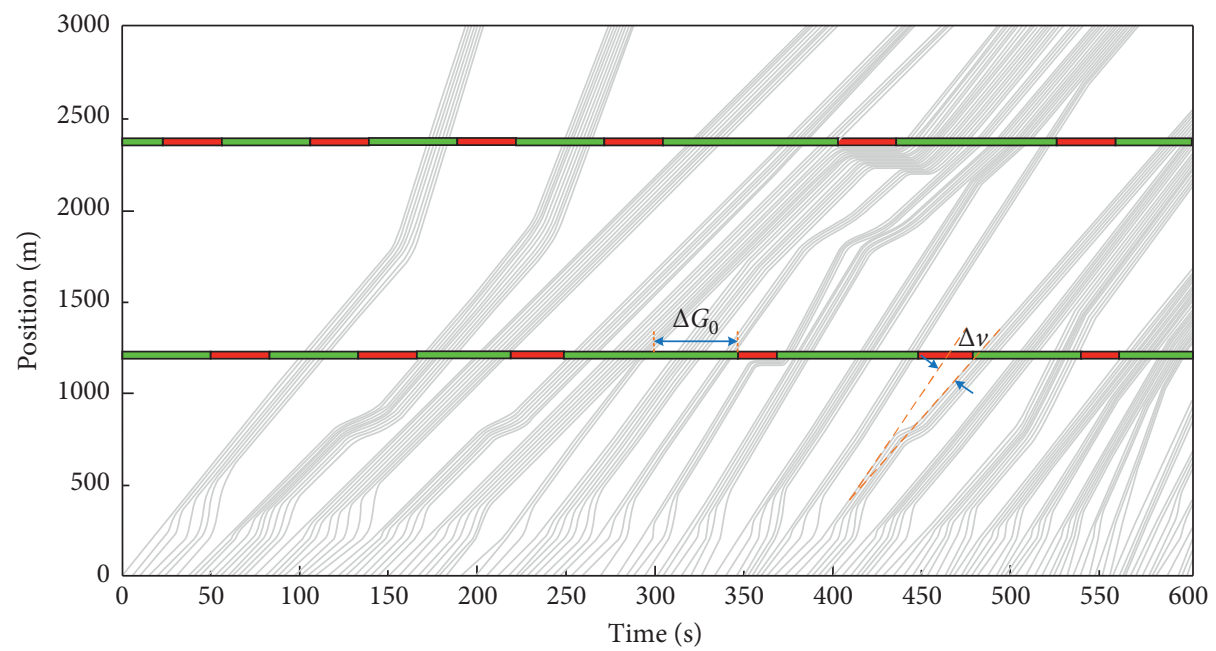

(c)

FIgURE 5: Vehicle space-time trajectory: (a) FC method; (b) FC-SG method; (c) FC-SG-SO method.

significantly reduced compared with those in Figure 5(a). $\Delta v$ in Figure $5(\mathrm{~b})$ is the slope (driving speed) of the fleet trajectory changes and is the speed guidance process. After guidance, the fleet can pass through the intersection during green light. As a result, waiting delays are reduced. Figure 5(c) shows the vehicle trajectories of the FC-SG-SO method. Only three fleets are in queue during the $600 \mathrm{~s}$ observation period. $\Delta G_{0}$ and $\Delta v$ in Figure 5(c) are the green light extension and speed guidance processes, respectively. The fleets obtain the right of passage in both cases, and they can pass through the intersection without waiting.

\subsection{Delay}

4.2.1. Vehicle Delays of Different Main Road Traffic Volumes. The traffic volume of the secondary road is set to $50 \mathrm{veh} / \mathrm{h}$ when analysing the influence of the main road vehicle arriving on delay, and the longest green time of the main road is $100 \mathrm{~s}$. The simulation results under different traffic volumes of 250 to $2000 \mathrm{veh} / \mathrm{h}$ of the main road are shown in Figure 6.

Figure 6(a) shows the delays of the three methods. According to the results, the delays increase with the increase in traffic volumes of the main road. When the traffic volumes exceed $1800 \mathrm{veh} / \mathrm{h}$, the delay caused by the FC and FC-SG methods increases quickly. Compared with the two methods, the FC-SG-SO method coordinates the fleet trajectory and signal phase better, and the delay is the least and exhibits no significant change even when the traffic volume rises to $1800 \mathrm{veh} / \mathrm{h}$.

Figure 6(b) shows the secondary road delay under different main road traffic volumes. Delays caused by the FC and FC-SG methods are similar, and delays increase with increasing main road traffic volume. The FC-SG-SO method is mainly concerned with the main road traffic flow; consequently, the secondary road delay is the largest.
The average delay of the entire intersection is shown in Figure 6(c). The various tendencies of intersection delay are similar to those of the main road delay and increase with increasing main road traffic volume. Although the FC-SGSO method causes the largest secondary road delay, the traffic volume on the secondary road is very low and has no effect on the total intersection delay.

\subsubsection{Delays of Different Secondary Road Traffic Volumes.} The traffic volume of the main road is permanently set to $800 \mathrm{veh} / \mathrm{h}$, and the longest green time is $100 \mathrm{~s}$. The minimum green time of the traffic direction under different traffic conditions of the secondary road is shown in Table 3 . The simulation results under different traffic volumes of the secondary road are shown in Figure 7.

Figure 7(a) shows that the main road delay caused by the FC method and the FC-SG method does not change evidently with increasing secondary traffic volume. The delay caused by the FC-SG-SO method is slightly increased, but the degree of increase is small. The increase is related to an increase in the minimum green time of the secondary road. The main road delay value of the FC-SG-SO method is lower than that of the FC or FC-SG method.

Figure 7(b) shows the secondary road delays. The delays caused by the FC and FC-SG methods increase with increasing traffic volume, and the delay caused by the FC-SG$\mathrm{SO}$ method slightly changes. The delay of the FC-SG-SO method increases with increasing secondary road traffic volume, but the value is smaller than those of the FC and FCSG methods. The reason is that the minimum green time of the secondary road increases; that is, the right of way increases as the traffic volume increases. As a result, the increase in delay weakens.

The delays of the entire intersection are shown in Figure $7(\mathrm{c})$. Among the delays, the total delay caused by the FC method is the largest, and the delay of the FC-SG-SO method is the smallest. 


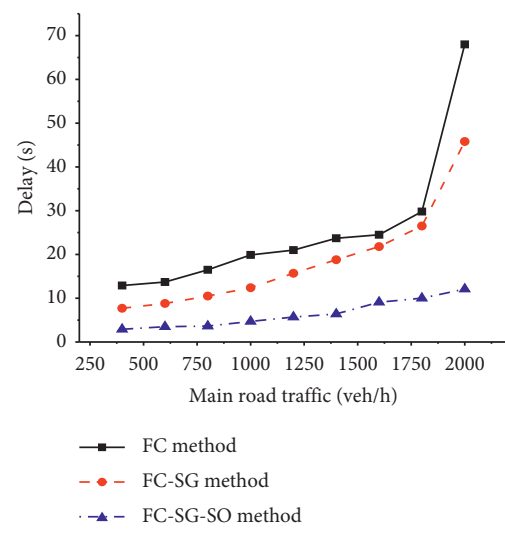

(a)

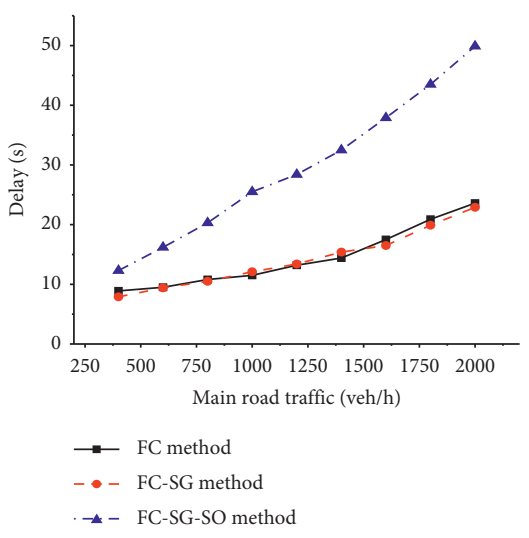

(b)

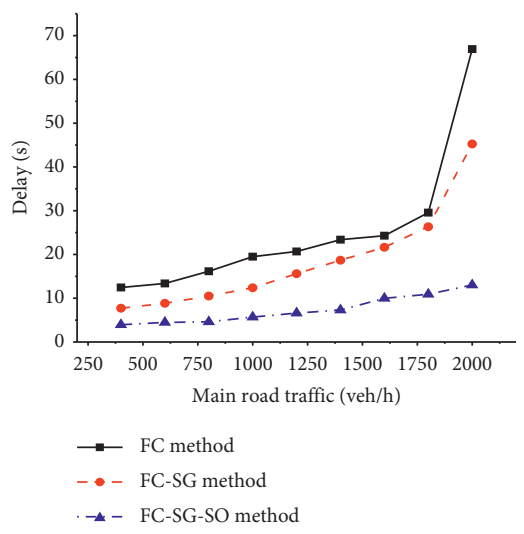

(c)

FIgURE 6: Delays under different traffic volumes of main road. (a) Main road delay. (b) Secondary road delay. (c) Total delay.

TABLE 3: Minimum green time for different traffic volumes of the secondary road.

\begin{tabular}{lr}
\hline Traffic volume (veh/h) (s) & Minimum green time \\
\hline 50 & 20 \\
100 & 20 \\
150 & 20 \\
200 & 25 \\
250 & 25 \\
300 & 25 \\
350 & 30 \\
400 & 30 \\
450 & 30 \\
\hline
\end{tabular}

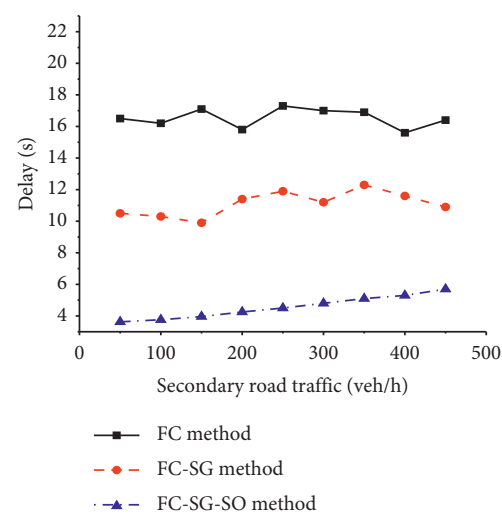

(a)

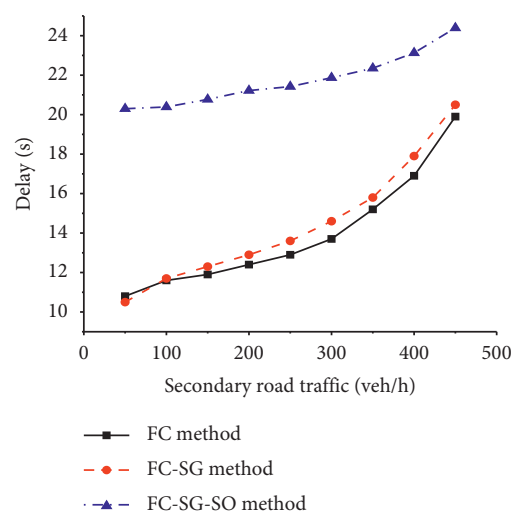

(b)

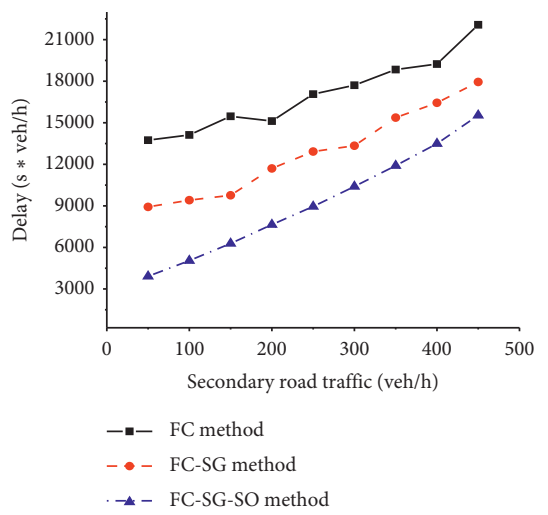

(c)

Figure 7: Delays under different traffic volumes of secondary roads. (a) Main road delay. (b) Secondary road delay. (c) Total delay.

\section{Conclusions}

Taking the low-visibility environment of a highway zone as the object, a comprehensive vehicle formation and trajectory optimization method is proposed. Some conclusions can be gained from the simulation and analysis. First, the reasonable FC-SG-SO method can not only avoid overlapping trajectories in each fleet but also reduce the delay of the fleet. Second, the improvement and supplementation of the FC method and the FC-SG method can effectively improve traffic safety and traffic efficiency in the low-visibility zone and better optimize fleet trajectory. Finally, different volumes have completely different effects on traffic delays of the main road, the secondary road, and the entire intersection. Meanwhile, the increase in traffic volume of the secondary road has less effect on the main road traffic delay.

The proposed method can be applied in low-visibility highway segments, especially highway segments with 
multiple signalized intersections. In reality, the complex composition of vehicles, driver reaction time, and vehicle braking performance in a highway segment affects the running speed of formation. Therefore, complex traffic factors are challenging tasks that require further investigation. In addition, the location of the low-visibility zone varies in some conditions. Thus, future works should consider moving the location of low-visibility highway segments when establishing a dynamic control method.

\section{Data Availability}

The data used to support the findings of this study are available from the corresponding author upon request.

\section{Conflicts of Interest}

The authors declare that there are no conflicts of interest regarding the publication of this paper.

\section{Acknowledgments}

This research was jointly sponsored by the National Natural Science Foundation of China (Grant nos. 52072108, 51878236, and 51675151) and the Fundamental Research Funds for the Central Universities (Grant no. JZ2019HGBZ0141).

\section{References}

[1] M.-B. Pang, S.-S. Zheng, and Z.-H. Cai, "Simulation of three lanes one-way freeway in low visibility weather by possible traffic accidents," Physica A: Statistical Mechanics and Its Applications, vol. 433, pp. 161-170, 2015.

[2] X. Y. Yang, "Study on the influence of fog on expressway and counter measures," Master's Thesis, Chang'an University, Xi'an, China, 2014

[3] O. A. Hjelkrem and E. O. Ryeng, "Chosen risk level during car-following in adverse weather conditions," Accident Analysis \& Prevention, vol. 95, pp. 227-235, 2016.

[4] Y. Peng, M. Abdel-Aty, Q. Shi, and R. Yu, "Assessing the impact of reduced visibility on traffic crash risk using microscopic data and surrogate safety measures," Transportation Research Part C: Emerging Technologies, vol. 74, pp. 295-305, 2017.

[5] G. Yannis, A. Kondyli, and N. Mitzalis, "Effect of lighting on frequency and severity of road accidents," Proceedings of the Institution of Civil Engineers-Transport, vol. 166, no. 5, pp. 271-281, 2013.

[6] Y. L. Pei and G. Z. Cheng, "Research on the relationship between discrete character of speed and traffic accident and speed management of freeway," China Highway Journal, vol. 17, no. 1, pp. 74-78, 2004.

[7] Y. Peng, M. Abdel-Aty, J. Lee, and Y. Zou, "Analysis of the impact of fog-related reduced visibility on traffic parameters," Journal of Transportation Engineering, Part A: Systems, vol. 144, no. 2, Article ID 04017077, 2018.

[8] K. Gao, H. Z. Tu, H. Shi, and Z. F. Li, "Effect of low-visibility in haze weather condition on longitudinal driving behavior in different car following stages," Journal of Jilin University (Engineering), vol. 47, no. 6, pp. 1716-1727, 2017.
[9] C. C. Li, X. M. Liu, and J. Rong, "Characteristics of vehicle speed for expressway under different visibility condition," Journal of Transportation Systems Engineering and Information Technology, vol. 14, no. 6, pp. 213-218, 2014.

[10] K. L. M. Broughton, F. Switzer, and D. Scott, "Car following decisions under three visibility conditions and two speeds tested with a driving simulator," Accident Analysis \& Prevention, vol. 39, no. 1, pp. 106-116, 2007.

[11] M. Saffarian, R. Happee, and J. C. F. D. Winter, "Why do drivers maintain short headways in fog? A driving-simulator study evaluating feeling of risk and lateral control during automated and manual car following," Ergonomics, vol. 55, no. 9, pp. 971-985, 2012.

[12] Z. Lu, T. J. Kwon, and L. Fu, "Effects of winter weather on traffic operations and optimization of signalized intersections," Journal of Traffic and Transportation Engineering (English Edition), vol. 6, no. 2, pp. 94-106, 2019.

[13] Y. Jiang, S. Li, and D. E. Shamo, "A platoon-based traffic signal timing algorithm for major-minor intersection types," Transportation Research Part B: Methodological, vol. 40, no. 7, pp. 543-562, 2006.

[14] X. F. Xie, G. Barlow, S. Smith, and Z. Rubinstein, "Platoonbased self-scheduling for real-time traffic signal control," in Proceedings of the International IEEE Conference on Intelligent Transportation Systems, vol. 263, pp. 879-884, October 2011, Washington, DC, USA.

[15] S. Lee and S. C. Wong, "Group-based approach to derivatives of delay models based on incremental queue accumulations for isolated signalized junctions," Transportmetrica $B$ : Transport Dynamics, vol. 7, no. 1, pp. 202-222, 2019.

[16] M. Amirgholy, M. Nourinejad, and H. O. Gao, "Optimal traffic control at smart intersections: automated network fundamental diagram," Transportation Research Part B: Methodological, vol. 137, pp. 2-18, 2020.

[17] H. Ding, H. Yuan, X. Zheng, H. Bai, W. Huang, and C. Jiang, "Integrated control for a large-scale mixed network of arterials and freeways," IEEE Intelligent Transportation Systems Magazine, p. 1, 2020.

[18] H. Liu, X.-Y. Lu, and S. E. Shladover, "Traffic signal control by leveraging cooperative adaptive cruise control (CACC) vehicle platooning capabilities," Transportation Research Part C: Emerging Technologies, vol. 104, pp. 390-407, 2019.

[19] R. Wunderlich, C. Liu, I. Elhanany, and T. Urbanik, "A novel signal-scheduling algorithm with quality-of-service provisioning for an isolated intersection," IEEE Transactions on Intelligent Transportation Systems, vol. 9, no. 3, pp. 536-547, 2008.

[20] R. Wunderlich, I. Elhanany, and T. Urbanik, “A stable longest queue first signal scheduling algorithm for an isolated intersection," in Proceedings of the 2007 IEEE International Conference on Vehicular Electronics \& Safety, pp. 1-6, Beijing, China, December 2007.

[21] H. Ding, Y. Di, X. Zheng, H. Bai, and W. Zhang, "Automated cooperative control of multilane freeway merging areas in connected and autonomous vehicle environments," Transportmetrica B: Transport Dynamics, vol. 9, no. 1, pp. 437-455, 2021.

[22] X. Han, R. Ma, and H. M. Zhang, "Energy-aware trajectory optimization of CAV platoons through a signalized intersection," Transportation Research Part C: Emerging Technologies, vol. 118, Article ID 102652, 2020.

[23] B. Gong, R. Wei, D. Wu, and C. Lin, "Fleet management for HDVs and CAVs on highway in dense fog environment," 
Journal of Advanced Transportation, vol. 2020, Article ID 8842730, 21 pages, 2020.

[24] L. Li and X. Chen, "Vehicle headway modeling and its inferences in macroscopic/microscopic traffic flow theory: a survey," Transportation Research Part C: Emerging Technologies, vol. 76, pp. 170-188, 2017.

[25] S. A. Gargoum and K. El-Basyouny, "Analyzing the ability of crash-prone highways to handle stochastically modelled driver demand for stopping sight distance," Accident Analysis and Prevention, vol. 136, Article ID 105395, 2020.

[26] J. Hu, S. Rakheja, and Y. Zhang, "Tire-road friction coefficient estimation under constant vehicle speed control," IFACPapersOnLine, vol. 52, no. 8, pp. 136-141, 2019.

[27] Y. Q. Yang, X. M. Liu, and Q. Yu, "Study on the relationship between three parameters of traffic flow," Journal of Beijing University of Technology, vol. 32, no. 1, pp. 43-47, 2006.

[28] W.-L. Jin and H. M. Zhang, "An instantaneous kinematic wave theory of diverging traffic," Transportation Research Part B: Methodological, vol. 48, pp. 1-16, 2013.

[29] M. H. Li, "Research on reasonable speed limit of urban expressway," Master's Thesis, Harbin Institute of Technology, Harbin, China, 2015.

[30] R. B. Wang and J. L. Wang, "Discussion on bus priority control strategy at signalized intersection," Journal of People's Public Security University of China (Natural Science Edition), vol. 16, no. 1, pp. 87-90, 2010.

[31] H. Ding, J. Zhou, X. Zheng, L. Zhu, H. Bai, and W. Zhang, "Perimeter control for congested areas of a large-scale traffic network: a method against state degradation risk: a method against state transfer risk," Transportation Research Part C: Emerging Technologies, vol. 112, pp. 28-45, 2020.

[32] H. Ding, Y. Zhang, X. Zheng, H. Yuan, and W. Zhang, "Hybrid perimeter control for two-region urban cities with different states," IEEE Transactions on Control Systems Technology, vol. 26, no. 6, pp. 2049-2062, 2018.

[33] P. S. Parsonson, R. W. Roseveare, and J. M. Thomas, "Small area detection at intersections approaches," Journal of Transportation Engineering.vol. 44, pp. 8-17, 1974. 